\title{
Relationship between Plasma Hypoxia Inducible Factor $1 \alpha$ in Type 2 Diabetes Mellitus with Malignancy and Without Malignancy
}

\author{
Rusdiana Rusdiana ${ }^{1 *}$, Sry Suryani Widjaja ${ }^{1}$, Maya Savira ${ }^{2}$, Dedi Ardinata ${ }^{2}$ \\ ${ }^{1}$ Department of Biochemistry, Medical Faculty, Universitas Sumatera Utara, Jl. dr. Medan, Indonesia; ${ }^{2}$ Department of Physiology, \\ Medical Faculty, Universitas Sumatera Utara, Jl. dr. Medan, Indonesia
}

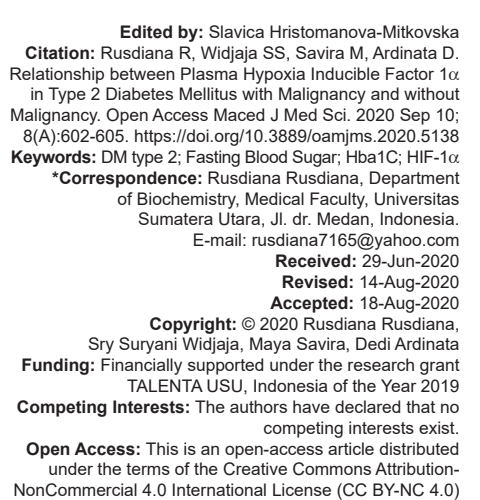

NonCommercial 4.0 International License (CC BY-NC 4.0)

\begin{abstract}
BACKGROUND: Diabetes mellitus was associated with hypoxia condition and result ischemia and induced neovascularization and other forms of the cell adaptation in response to the tissue concentrations of low oxygen levels. Hypoxia-Inducible Factor 1 alpha a marker of the cell adaptation as a hypoxic cell response which was due of chronic hiperglycemia.

AIM: The aim of this study to know the relationship between Hba1c and plasma HIF-1 $\alpha$ level at type 2 diabetes mellitus patients.

METHODS: The cross-sectional study design using the 89 samples of diabetes mellitus patients who attended Murni Teguh Hospital in Medan of Indonesia country. The inclusion criteria of the samples were all the patients diagnosed with type 2 diabetes mellitus both the sexes. Body mass index, blood pressure, and disease history six socioeconomic status was recorded. The laboratory parameters, including fasting blood sugar and Hba1c were examined by Murni Teguh Hospital Laboratory.

RESULTS: The result of the study we found that there was no significant difference the hypoxia-inducible factor $1 \alpha$ level (HIF-1 $\alpha)$ at type 2 diabetes mellitus with malignancy was higher compared at type 2 diabetes mellitus without malignancy.

CONCLUSION: The patient's type 2 diabetes mellitus with the high HIF-1 $\alpha$ levels have a poor prognosis compared with the lower levels because the high HIF- $1 \alpha$ will tend to have a risk complication of malignancy or the other complication of diabetes mellitus.
\end{abstract}

\section{Introduction}

Diabetes mellitus (DM) is a progressive chronic disease caused by years of insulin resistance and hyperinsulinemia before the development of hyperglycemia. Previously, the prediabetes phase could have been more than 10 years before being diagnosed with Type 2 diabetes mellitus, where this phase is often referred to as a metabolic syndrome, where this condition is always compared to abdominal obesity, failure of glucose tolerance, dyslipidemia, and hypertension [1]. Reliable, fasting blood sugar level was measured by measuring hemoglobin glycosylate concentration (HbA1C). HbA1C was specific hemoglobin with the glucose that binds to free amino acid groups formed from non-enzymatic reactions by hemoglobin which are exposed to high glucose levels in the plasma. The relationship between $\mathrm{HbA} 1 \mathrm{C}$ and glucose in blood plasma is very complex. Routinely $\mathrm{HbA} 1 \mathrm{c}$ is used as a diagnostic tool to measure glucose levels in the blood and can be used to predict the risk of developing complications in DM patients [2].

Diabetes mellitus is often associated with a state of hypoxia and results in ischemia which induced neovascularization and other forms of the cell adaptation in response to tissue concentrations of low oxygen levels. The cell adaptation response to hypoxia is relaxed by a marker called hypoxia-induction factor- $1 \alpha$ $(\mathrm{HIF}-1 \alpha)$, where a condition that changes hyperglycemia becomes a loss of cellular response to hypoxia in most complications of diabetes. Hypoxia interacts with hyperglycemia resulting in complications [3]. Hypoxiainducible factor- $1 \alpha$ (HIF- $1 \alpha$ ) was a critical transcription factor involved in oxygen homeostasis that regulates various adaptive responses to hypoxia, including angiogenesis, metabolic processes, and survival. Thus, the destabilization of HIF-1 tends to hurt the cell and tissue adaptation to low oxygen [4], [5]. Both hyperglycemia and hypoxia were important features of diabetes complications and appear to cause some adverse effects, which lead to complications such as diabetic retinopathy, poor wound healing, neuropathy, cardiovascular disease, and kidney [6]. In normoxic conditions, HIF $1 \alpha$ is degraded and this process is oxygen-dependent [7]. Hyperglycemia regulates the stability and function of HIF-1 $\alpha$ [8].

In the previous study, there was a relationship between HIF-1 $\alpha$ and type 2 diabetes mellitus and patients with hyperglycemia showed elevated levels 
of HIF-1 $\alpha$ [9]. Moreover, the research conducted in patients with diabetes mellitus with retinopathy found an increase in levels of HIF-1 $\alpha$ compared with type 2 diabetes mellitus without retinopathy [10]. Recently, a study showed that serum HIF-1 $\alpha$ in diabetic patients with breast cancer significantly higher than in the normal population [11]. Because of many, the previous studies have found a significant relationship between increasing levels of the HIF-1 $\alpha$ with type 2 diabetes mellitus, also the relationship with malignancy so that in this research we aimed to determine how is the HIF-1 $\alpha$ level at type 2 diabetes mellitus with malignancy and without malignancy who attend to Murni Teguh Hospital in Medan city, North Sumatera, Indonesia.

\section{Materials and Methods}

\section{Subjects}

We included 89 (average age $58.22 \pm 9.051$ years, $40.4 \%$ men and $59.6 \%$ female) consecutive type 2 diabetes mellitus with malignancy and type 2 diabetes mellitus without malignancy, between January and July 2019, who came to Murni Teguh Hospital in Medan, North Sumatera, Indonesia, according to ADA and $\mathrm{WHO}$ guidelines. The samples were composed of all type 2 diabetes mellitus with or without malignancy both male and female, without exception the age and treatment. The exclusion criteria were type 1 diabetes mellitus. Physical examinations were performed to record patient demographics, including height, weight, body mass index (BMI), and blood pressure. All participants were provided written informed consent at the visits. This study complied with the Declaration of Helsinki. Our study was approved by our institutional Health Research Ethics Committee with number 484/ TGL/KEPK FK USU-RSUP HAM 2019.

\section{Biochemical measurements}

Blood samples were collected from subjects at a visit to the outpatient clinic after an overnight fast. The samples were centrifuged at $3000 \mathrm{rpm}$ at $4^{\circ} \mathrm{C}$ for $15 \mathrm{~min}$. The supernatants were decanted and frozen at $-80^{\circ} \mathrm{C}$ until assayed. Fasting blood sugar (FBS) and $\mathrm{Hba1c}$ were measured using standard methods. Enzyme-linked immunosorbent assay (ELISA) kits were used to measure serum levels of HIF-1 $\alpha$ (Cayman Chemical Co, Ann Arbor, Michigan, USA). The plate has been pre-coated with the human HIF-1 $\alpha$ antibody. HIF- $1 \alpha$ present in the sample is added and binds to antibodies coated on the wells. And then biotinylated human HIF-1 $\alpha$. The antibody is added and binds to HIF- $1 \alpha$ in the sample. The substrate solution is then added and color develops in proportion to the amount of human HIF- $1 \alpha$. The reaction is terminated by the addition of acidic stop solution and absorbance. is measured at $450 \mathrm{~nm}$. Intra-assay and inter-assay coefficients of variation for HIF- $1 \alpha$ were $<8 \%$ and $<10 \%$, respectively.

\section{Statistical analysis}

Statistical analysis SPSS version 24.0 (SPSS Inc, Chicago, Illinois) statistical software was used for statistical analysis. We used the Shapiro-Wilk normality test. Continuous variables in normal distribution were compared using the Student's t-test. To assess the value of serum HIF-1 $\alpha$, we used nonparametric analysis.

\section{Results and Discussion}

A total of 89 consecutive samples in this research that 36 samples $(40.4 \%)$ were man and 53 samples $(59.6 \%)$ were female. In this research, the minimum age of the samples was 37 years and a maximum of the age was 77 years, where the mean age of the samples was $58.22 \pm 9.05$ years old. We have a minimum body mass index (BMI) of the samples were 18.55 and a maximum of $\mathrm{BMI}$ was $21.84 \mathrm{~kg} / \mathrm{m}^{2}$ and the mean of the BMI was $25.38 \pm 4.57 \mathrm{~kg} / \mathrm{m}^{2}$. The minimum of the Fasting blood sugar levels (FBS) of the sample $83 \mathrm{mg} / \mathrm{dL}$ and a maximum of $635 \mathrm{mg} / \mathrm{dL}$, where the mean of FBS was $243.55 \pm 97.664 \mathrm{mg} / \mathrm{dL}$.

In this study that we found that the mean of the fasting blood sugar level (FBS) at the patients in type 2 diabetes mellitus with malignancy $260.45 \pm 16.69 \mathrm{mg} / \mathrm{dL}$ and without malignancy $89.46 \pm 12.78 \mathrm{mg} / \mathrm{dL}$, the mean of $\mathrm{Hba1c}$ value of the diabetes mellitus with malignancy patients $7.573 \pm 0.357 \%$ and the mean of Hba1c value of the diabetes mellitus without malignancy patients $9.34 \pm 0.232 \%$, the mean of the HIF- $1 \alpha$ of the diabetes mellitus with malignancy patients $1.67 \pm 0.59 \mathrm{ng} / \mathrm{ml}$, and the mean of the HIF- $1 \alpha$ of the without malignancy $0.69 \pm 0.12 \mathrm{ng} / \mathrm{ml}$ (Table 1).

In our study, using statistics, we found that there was no difference significantly HIF-1 $\alpha$ at type 2 diabetes mellitus with malignancy and type 2 diabetes mellitus without malignancy ( $p>0.0005)$. Diabetes mellitus is characterized by defects in hypoxia-induced neovascularization in the myocardium, skeletal muscle, nerves, and skin [12]. In this study, we found of the samples that the HIF- $1 \alpha$ level at type 2 diabetes mellitus with malignancy patients was higher than without malignancy. As we know that HIF-1 $\alpha$ was a major factor to regulate oxygen homeostasis and plays a key role in many physiologic and pathology processes [13] and hyperglycemia regulates HIF- $1 \alpha$ protein stability and functions, destabilizing it, ultimately resulting in poor cell and tissue responses to hypoxia [14]. In this research that fasting blood sugar (FBS) at both of the samples, 
the mean was above the normal value. Moreover, this research, there was a significant difference between Hba1c at type 2 diabetes mellitus with malignancy and without malignancy $(p<0.0005)$.

In this cross-sectional study in type 2 diabetes mellitus subjects, we first evaluated the fasting blood sugar and $\mathrm{Hba} 1 \mathrm{c}$, and then we evaluated the HIF-1 $\alpha$ level. Previous studies have clarified the relationship between HIF-1 $\alpha$ and diabetes. Jiang et al. found that inhibition of HIF-1 in adipose tissue ameliorates obesity and insulin resistance [15]. The other research by Li et al. with coronary artery calcification in asymptomatic type 2 diabetic patients showed that a significantly increased in serum HIF-1 $\alpha$ level [16]. This may be caused not only by myocardial anoxia reflex but also due to hypoxic levels in the local tissue. Research by Catrina et al. reports that hyperglycemia impairs hypoxia-dependent stabilization of HIF-1 $\alpha$, where the research suggests a mechanism of cross-coupling between two of the most important determinants of the chronic complications in diabetes mellitus hyperglycemia and hypoxia [7]. This research no significant difference $\mathrm{HIF}-1 \alpha$ at type 2 diabetes mellitus with malignancy and type 2 diabetes mellitus without malignancy. Hypoxia has a prominent effect on all diabetic complications. Hyperglycemia regulates HIF-1 $\alpha$ protein stability and functions, destabilizing it, ultimately resulting in poor cell and tissue responses to hypoxia. Hypoxia may interact with hyperglycemia and promote diabetes and its complications [15]. Adaptive responses of cells to hypoxia are mediated by hypoxiainducible factor-1 (HIF-1), in particular, by $\mathrm{HIF}-1 \alpha$. Research has shown that increased angiogenesis is closely associated with the HIF- $1 \alpha$ pathway, and the HIF-1 $\alpha$ axis plays a pivotal role in malignancy [17]. In this research, there was no significant difference HIF- $1 \alpha$ at type 2 diabetes mellitus with and without malignancy. The mean of HIF-1 $\alpha$ at type 2 diabetes mellitus with malignancy $1.67 \mathrm{ng} / \mathrm{ml}$ and type 2 diabetes mellitus without malignancy $0.69 \mathrm{ng} / \mathrm{ml}$ (Table 2). As we know that the diabetes mellitus disease relationship with hypoxia and hypoxia interacts with hyperglycemia resulting in Table 1: Characteristic of the samples

\begin{tabular}{llllll}
\hline & \multicolumn{5}{l}{ Characteristic of the samples } \\
\cline { 2 - 6 } & $\mathrm{n}$ & Minimum & Maximum & Mean & Standard deviation \\
\hline Age & 89 & 37 & 77 & 58.22 & 9.051 \\
BMI & 89 & 18.55 & 41.84 & 25.3825 & 4.57065 \\
FBS & 89 & 83 & 635 & 243.55 & 97.664 \\
Hba1c & 89 & 2.4 & 14.0 & 8.545 & 2.1146 \\
HIF-1a & 89 & 0.00 & 17.80 & 1.1283 & 2.60571 \\
Valid N (listwise) & 89 & & & & \\
\hline
\end{tabular}

complications and malignancy, the complication of type 2 diabetes mellitus occurs hypoxia process; this is due to the limited oxygen supply during the process

Table 2: Characteristic of the group statistics

\begin{tabular}{llllll}
\hline & & $\mathrm{n}$ & Mean & $\begin{array}{l}\text { Standard } \\
\text { deviation }\end{array}$ & $\begin{array}{l}\text { Standard error } \\
\text { mean }\end{array}$ \\
\hline FBS & DM with malignancy & 40 & 260.45 & 105.55 & 16.69 \\
& DM without malignancy & 49 & 229.76 & 89.47 & 12.78 \\
Hba1c & DM with malignancy & 40 & 7.57 & 2.26 & 0.357 \\
& DM without Malignancy & 49 & 9.34 & 1.62 & 0.232 \\
& DM with malignancy & 40 & 1.67 & 3.73 & 0.59 \\
& DM without malignancy & 49 & 0.69 & 0.84 & 0.12 \\
\hline
\end{tabular}

of rapid anabolic cell proliferation. Hence, the samples in this research both type 2 diabetes mellitus with or without malignancy found that hypoxia area. This study used samples with all types of malignancies and does not classify types of samples with certain malignancies, then also does not classify samples that have received anticancer therapy and have not received therapy with anti-cancer.

\section{Conclusion}

Although in this study we found that there was no significant difference HIF-1 $\alpha$ at type 2 diabetes mellitus with malignancy and without malignancy, the patients type 2 diabetes mellitus with the high HIF-1 $\alpha$ levels have a poor prognosis compared with the lower levels because the high HIF-1 $\alpha$ will tend to have a risk complication of malignancy or the other complication of diabetes mellitus.

\section{Acknowledgments}

The authors gratefully acknowledge that the present research is supported by the Ministry of Research and Technology and Higher Education Republic, Indonesia. The support is under the research grant TALENTA USU of the Year 2019.

\section{References}

1. Alberti KG. Screening and diagnosis of prediabetes: Where are we headed? Diabetes Obes Metab. 2007;9 Suppl 1:12-6. https://doi.org/10.1111/j.1463-1326.2007.00764.x PMid:17877542

2. Verma M, Paneri S, Badi P, Raman PG. Effect of increasing duration of diabetes mellitus Type 2 on glycated hemoglobin and insulin sensitivity. Indian J Clin Biochem. 2006;21(1):142-6. https://doi.org/10.1007/bf02913083 PMid:23105586

3. Cameron NE, Eaton SE, Cotter MA, Tesfaye S. Vascular factors and metabolic interactions in the pathogenesis of diabetic neuropathy. Diabetologia. 2001;44(11):1973-88. https://doi. org/10.1007/s001250100001

PMid:11719828

4. Giovannucci E, Harlan DM, Archer MC, Bergenstal RM, Gapstur SM, Habel LA, et al. Diabetes and cancer: A consensus report. Diabetes Care. 2010;33(7):1674-85. https://doi. org/10.2337/dc10-0666 PMid:20587728

5. Ivan M, Kondo K, Yang H, Kim W, Valiando J, Ohh M, etal. HIFalpha targeted for VHL-mediated destruction by proline hydroxylation: 
Implications for O2 sensing. Science. 2001;292(5516):464-8. https://doi.org/10.1126/science.1059817

\section{PMid:11292862}

6. Jaakkola P, Mole DR, Tian YM, Wilson MI, Gielbert J, Gaskell SJ, et al. Targeting of HIF-alpha to the Von Hippel-Lindau ubiquitylation complex by O2-regulated prolyl hydroxylation. Science. 2001;292(5516):468-72. https://doi.org/10.1126/science.1059796 PMid:11292861

7. Catrina SB, Okamoto K, Pereira T, Brismar K, Poellinger L. Hyperglycemia regulates hypoxia-inducible factor-1alpha protein stability and function. Diabetes. 2004;53(12):3226-32. https://doi.org/10.2337/diabetes.53.12.3226

PMid:15561954

8. Hu M, Polyak K. Microenvironmental regulation of cancer development. Curr Opin Genet Dev. 2008;18(1):27-34.

PMid:18282701

9. Talks KL, Turley H, Gatter KC, Maxwell PH, Pugh CW, Ratcliffe PJ, et al. The expression and distribution of the hypoxia-inducible factors HIF-1alpha and HIF-2alpha in normal human tissues, cancers, and tumor-associated macrophages. Am J Pathol. 2000;157(2):411-21. https://doi.org/10.1016/ s0002-9440(10)64554-3

PMid:10934146

10. Hoo Y, Mahmoud AA. Hypoxia inducible factor- $1 \alpha$ in Type 2 diabetes mellitus with microalbuminuria and retinopathy. Majalah Kedokt Bandung Med J. 2014;46(2):100-5.

11. Ece H, Cigdem E, Yuksel K, Ahmet D, Hakan E, Oktay TM. Use of oral antidiabetic drugs (Metformin and Pioglitazone) in diabetic patients with breast cancer: How does it effect serum Hif-1 alpha and 80 hdg levels? Asian Pac J
Cancer Prev. 2012;13(10):5143-8. https://doi.org/10.7314/ apjcp.2012.13.10.5143

PMid:23244125

12. Martin A, Komada MR, Sane DC. Abnormal angiogenesis in diabetes mellitus. Med Res Rev. 2003;23(2):117-45. https://doi. org/10.1002/med.10024

PMid:12500286

13. Eltzschig HK, Carmeliet P. Hypoxia and inflammation. N Engl J Med. 2011;364(7):656-65.

PMid:21323543

14. Ke QD, Costa M. Hypoxia-inducible factor-1 (HIF-1). Mo Pharmacol. 2006;70(5):1469-80. https://doi.org/10.1124/ mol.106.027029

PMid:16887934

15. Bento CF, Pereira P. Regulation of hypoxia-inducible factor 1 and the loss of the cellular response to hypoxia in diabetes. Diabetologia. 2011;54(8):1946-56. https://doi.org/10.1007/ s00125-011-2191-8

PMid:21614571

16. Li G, Lu WH, Ai R, Yang JH, Chen F, Tang ZZ. The relationship between serum hypoxia-inducible factor $1 \alpha$ and coronary artery calcification in asymptomatic Type 2 diabetic patients. Cardiovasc Diabetol. 2014;13:52. https://doi.org/10.1186/1475-2840-13-52 PMid:24564828

17. Garcia-Maceira P, Mateo J. Silibinin inhibits hypoxia-inducible factor-1alpha and mTOR/p70S6K/4E-BP1 signalling pathway in human cervical and hepatoma cancer cells: Implications for anticancer therapy. Oncogene. 2009;28():313-24. https://doi. org/10.1038/onc.2008.398

PMid:18978810 